
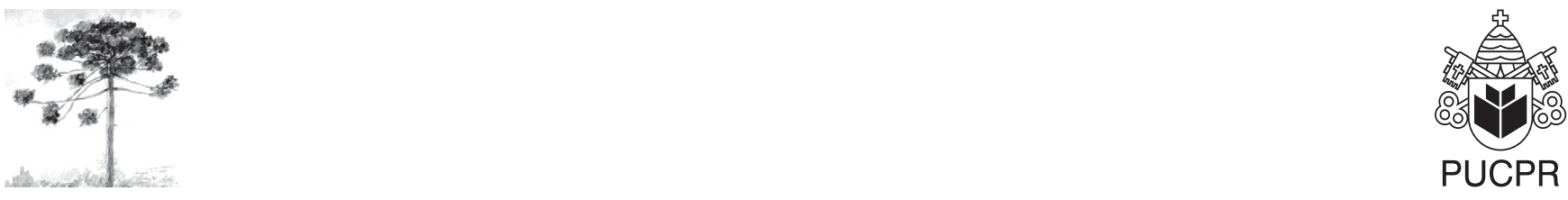

\title{
Avaliação dos resíduos líquidos em um sistema de abate de bovinos
}

\author{
Liquid residues evaluation in a cattle slaughter system recycling
}

\author{
Marina Moura Morales ${ }^{[a]}$, Cristiane Almeida Neves Xavier ${ }^{[b]}$, \\ Adriane de Andrade Silva ${ }^{[c]}$, Jorge de Lucas Junior ${ }^{[\mathrm{d}]}$
}

[a] Departamento de Energia na Agricultura Universidade Estadual de São Paulo (UNESP), Botucatu, SP - Brasil, e-mail: marinamm@fca.unesp.br

[b] Departamento de Engenharia Rural, Faculdade de Ciências Agrárias e Veterinárias Universidade Estadual de São Paulo (FCAV UNESP), Jaboticabal, SP - São Paulo: e-mail: crisanx@yahoo.com.br

[c] Departamento de Engenharia Rural, Faculdade de Ciências Agrárias e Veterinárias Universidade Estadual de São Paulo (FCAV UNESP), Jaboticabal, SP - São Paulo: e-mail: zoodrika@uol.com.br

[d] Departamento de Engenharia Rural, Faculdade de Ciências Agrárias e Veterinárias Universidade Estadual de São Paulo (FCAV UNESP), Jaboticabal, SP - São Paulo: e-mail: jlucas@fcav.unesp.br

\section{Resumo}

O Brasil apresenta grandes potencialidades na produção de alimentos, porém, as formas empregadas para atendimento desta demanda têm levado ao aumento da geração de resíduos, fato que justifica o estudo de práticas de reciclagem, como a biodigestão anaeróbia desses materiais, pois, além da agregação de valor devido à transformação de resíduos potencialmente poluidores em adubo orgânico e geração de energia (biogás), ainda contribui para um saneamento eficaz. No desenvolvimento deste trabalho foi realizada a caracterização dos resíduos líquidos produzidos no sistema de abate de bovinos. Foram realizadas as coletas e análises de amostras compostas em oito pontos do processo de tratamento de resíduos do abatedouro: antes do flotador, depois do flotador, antes da peneira, depois da peneira, efluente do biodigestor 1 , efluente do biodigestor 2 , afluente das lagoas de polimento e efluentes das lagoas de polimento. Foram avaliados os teores de sólidos totais (ST) e de sólidos voláteis ( $\mathrm{SV}$ ), pH, demanda química de oxigênio (DQO), demanda bioquímica de oxigênio (DBO) e quantificação dos teores dos $\mathrm{N}, \mathrm{P}, \mathrm{K}, \mathrm{Ca}, \mathrm{Mg}, \mathrm{Co}, \mathrm{Fe}, \mathrm{Cu}, \mathrm{Zn}, \mathrm{Mn}, \mathrm{Na}$ e Ni. No afluente e efluente das lagoas de polimento foram analisados, ovos viáveis de helmintos, Salmonella sp. e coliformes totais e fecais. A biodigestão anaeróbia poderia ter apresentado resultados mais satisfatórios, o que não ocorreu em virtude dos biodigestores estarem em fase de partida. Não houve ocorrência de ovos viáveis de helmintos e de Salmonella sp. As 
amostras analisadas e os valores de coliformes totais e fecais apresentaram-se abaixo do permitido pela resolução CONAMA 357/05.

Palavras-chave: Biodigestão anaeróbia. Resíduo. Abatedouro de bovinos.

\begin{abstract}
Brazil has a high potential in food production industry, but the procedures used to attend its demand had led to increasing residues. This fact justifies the recycling practices and studies like anaerobic digestion for these materials, because, can led a value aggregation due to residues transformations from potential pollutants to organic fertilizers and energy (biogas) and still have efficient sanitation. During the experiment the bovine slaughter residues was done through liquid residues characterization. It was done by collecting and analyzing samples at the eight points of residue treatment process: before floater, after floater, before sieve, after sieve, digester effluent 1 , digester effluent 2, polishing pond affluent, and polishing pond effluent. TS, VS, pH, COD, BOD, N, P, K, $\mathrm{Ca}, \mathrm{Mg}, \mathrm{Co}, \mathrm{Fe}, \mathrm{Cu}, \mathrm{Zn}, \mathrm{Mn}, \mathrm{Na}$ and $\mathrm{Ni}$ was analyzed. Viable helminth eggs, Salmonella sp., total and fecal coliform were analyzed in the polish pond affluent and effluent. The anaerobic digestion could have presented more satisfactory results if the digesters were not in starting phase. There were neither viable helminth eggs nor Salmonella sp. occurrence in the analyzed samples and the total and fecal coliform. Most Provable Number (MPN) were lower than permitted by the Brazilian law (CONAMA 357/05).
\end{abstract}

Keywords: Anaerobic digestion. Residue. Cattle slaughter.

\section{Introdução}

A crescente demanda por alimentos tem feito a agropecuária moderna acentuar sua participação nos impactos provocados ao ambiente. Cada vez mais, torna-se necessário o desenvolvimento de sistemas de produção sustentáveis, o que a Unesco (1) definiu como aqueles que permitem atender às necessidades presentes sem comprometer a capacidade das futuras gerações em responder às suas próprias necessidades.

O crescente aumento do abate de bovinos no Brasil, com consequente aumento de resíduos líquidos (água residuária), fez com que os abatedouros tenham procurado se adequar às exigências da Legislação Ambiental.

$\mathrm{Na}$ busca de atender a esta demanda, diversos sistemas vêm sendo implementados para tratamento e destinação mais adequada dos resíduos. Pela análise do fluxograma (Figura 1) de produção, devem-se realizar estudos para adequar quais são os procedimentos mais apropriados e quais condições de manejo que melhor atendem ao tratamento e à disposição dos resíduos.

Os sistemas de tratamento por biodigestão anaeróbia são particularmente apropriados para esses resíduos, uma vez que atendem às suas particularidades, além de incrementar a economia racionalizando o uso dos recursos naturais, com redução no consumo de água e energia, promovendo a reciclagem dos resíduos.

Para os resíduos líquidos, gerados em abundância cujas características mostram elevado teor de umidade, a biodigestão anaeróbia é adequada, pois dispensa o acréscimo de água e de quantidades consideráveis de nutrientes, que são essenciais para o desenvolvimento e manutenção dos microrganismos que participam do processo.

Baseado na relevância da necessidade de se caracterizar e avaliar os processos e produtos dos tratamentos aplicados nos resíduos gerados no abatedouro de bovinos, foi avaliada a biodigestão anaeróbia dos resíduos líquidos.

\section{Material e métodos}

Os resíduos utilizados foram coletados no Abatedouro e Frigorífico, situado na cidade de Lins, SP, e analisados no Laboratório de Biodigestão Anaeróbia da Faculdade de Ciências Agrárias e Veterinárias (FCAV), Câmpus de Jaboticabal, da Universidade Estadual Paulista (Unesp). 


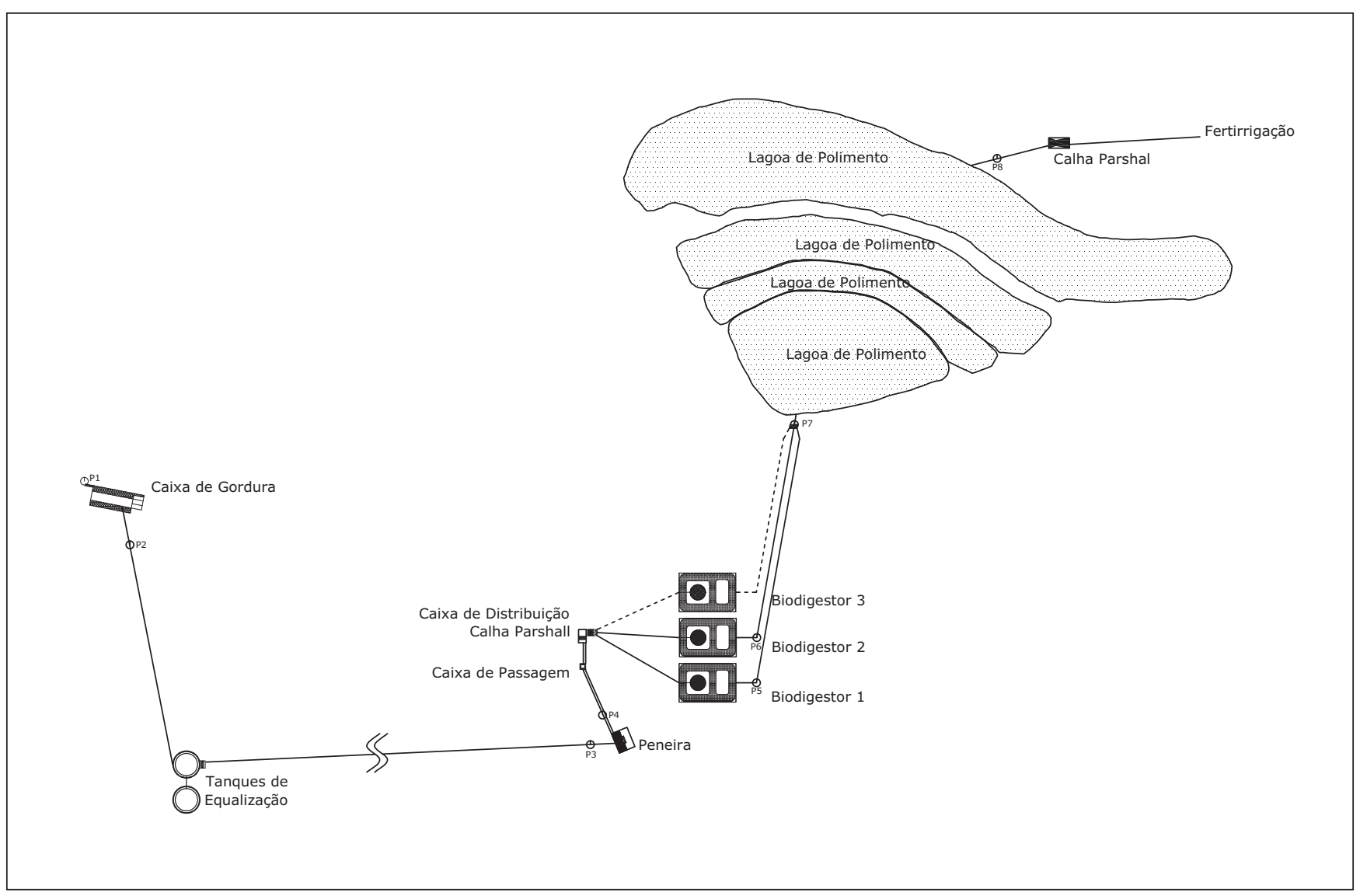

Figura 1 - Fluxograma do sistema de tratamento de água residuária do abatedouro de bovinos

Foram coletados os resíduos líquidos nos seguintes pontos:

- P1 (linha vermelha antes da caixa de gordura): composto pelas águas de lavagem da sala de sangria, lavagem da carcaça, limpeza dos equipamentos, limpeza da graxaria e água de cozimento;

- P2 (linha vermelha após a caixa de gordura): composto pelas mesmas águas do ponto 1 ;

- P3 (linhas vermelha e verde antes da peneira): compostas pelas águas mencionadas no ponto 1 e 2 , além da água de banho, limpeza dos currais e lavagem do conteúdo ruminal;

- P4 (afluente dos biodigestores): compostas pelas mesmas águas do ponto 3;

- P5 (efluente do biodigestor 1): compostas pelas mesmas águas do ponto 3;
- P6 (efluente do biodigestor 2): compostas pelas mesmas águas do ponto 3;

- P7 (efluente biodigestores 1 e2): afluente das lagoas de polimento;

- P8: afluente das lagoas de polimento.

Os pontos descritos estão representados no fluxograma do sistema de tratamento de abate de bovinos (Figura 1).

As amostras de águas residuárias foram compostas por alíquotas retiradas de hora em hora. Nos pontos P1 e P2 foram coletadas durante o período de 10 horas e os pontos P3, P4, P5 e P6 durante o período de 24 horas, no início de fevereiro de 2006, para caracterização dos teores de sólidos totais (ST), sólidos voláteis (SV), pH, demanda química de oxigênio (DQO), demanda bioquímica de oxigênio (DBO) e quantificação dos teores de nutrientes $(\mathrm{N}, \mathrm{P}, \mathrm{K}, \mathrm{Ca}, \mathrm{Mg}, \mathrm{Co}, \mathrm{Fe}, \mathrm{Cu}, \mathrm{Zn}, \mathrm{Mn}$, além dos elementos $\mathrm{Na}$ e $\mathrm{Ni}$ ). 
As amostras coletadas nos pontos $\mathrm{P} 7 \mathrm{e}$ P8, foram compostas por alíquotas retiradas de hora em hora, coletadas durante o período de 10 horas, no início de julho do mesmo ano, para caracterização dos teores de sólidos totais (ST), sólidos voláteis (SV), $\mathrm{pH}$, demanda química de oxigênio (DQO), demanda bioquímica de oxigênio (DBO), quantificação dos teores de nutrientes $(\mathrm{N}, \mathrm{P}, \mathrm{K}, \mathrm{Ca}, \mathrm{Mg}, \mathrm{Co}, \mathrm{Fe}, \mathrm{Cu}, \mathrm{Zn}$, $\mathrm{Mn}$, além de $\mathrm{Na}$ e Ni), ovos de helmintos (2), Salmonela sp. $(3,4)$ e NMP de coliformes totais e fecais (5).

\section{Caracterizaçáo dos tratamentos da água residuária}

O Abatedouro e Frigorífico estudado possui dois biodigestores do tipo UASB (Upflow Anaerobic Sludge Blanket Reactor), com volume de 7 milhões de litros cada e um em construção, além de quatro lagoas de polimento, a primeira com $2 \mathrm{~m}$ de profundidade, $113 \mathrm{~m}$ de comprimento e $70 \mathrm{~m}$ de largura; a segunda com $2 \mathrm{~m}$ de profundidade, $302 \mathrm{~m}$ de comprimento e $28 \mathrm{~m}$ de largura; a terceira com $2 \mathrm{~m}$ de profundidade, $370 \mathrm{~m}$ de comprimento, 42 $\mathrm{m}$ de largura; e a quarta com $2 \mathrm{~m}$ de profundidade, $585 \mathrm{~m}$ de comprimento, $70 \mathrm{~m}$ de largura.

\section{Resultados e discussão}

Os valores dos pontos P7 e P8 (Tabela 1) apresentaram discrepâncias em relação aos demais, pois as amostras foram coletadas em épocas diferentes. Isso se deu pelos sistemas de tratamento de efluentes estarem em fase de partida, variando em função do tempo.

$\mathrm{O}$ valor de $\mathrm{DBO}$ apresentado no experimento foi de 1050 a $2200 \mathrm{mg}^{-1}$, sendo que Brile (6), trabalhando com o mesmo tipo de resíduo, encontrou valores de DBO oscilando entre 800 a $32.000 \mathrm{mg} \mathrm{L}^{-1}$.

Tabela 1 - Caracterização da água residuária de abatedouro de bovinos

\begin{tabular}{|c|c|c|c|c|c|c|c|c|}
\hline \multirow[b]{2}{*}{ Parâmetros } & P1* & P2* & P3* & P4* & P5* & P6* & P7* & P8* \\
\hline & \multicolumn{8}{|c|}{$\mathrm{mg} \mathrm{L}^{-1}$} \\
\hline DQO & 4297 & 2963 & 3416 & 3187 & 3071 & 2032 & 1373 & 589 \\
\hline DBO & 2150 & 1750 & 2025 & 2200 & 1475 & 1050 & 1850 & 1800 \\
\hline ST & 0,49 & 0,50 & 0,41 & 0,38 & 0,33 & 0,38 & 0,68 & 0,52 \\
\hline SV & 99,99 & 99,87 & 99,74 & 99,78 & 99,31 & 99,80 & 99,49 & 99,48 \\
\hline $\mathrm{pH}$ & 6,92 & 6,97 & 6,85 & 6,87 & 7,13 & 7,02 & 7,47 & 6,29 \\
\hline $\mathrm{N}$ & 0,46 & 0,29 & 0,03 & 0,17 & 0,14 & 0,25 & 0,2 & 0,17 \\
\hline $\mathrm{P}$ & 0,14 & 0,14 & 0,17 & 1,9 & 1,52 & 1,25 & 0,011 & 0,005 \\
\hline K & 0,09 & - & 0,9 & 0,68 & 0,85 & 0,41 & 1,58 & 1,44 \\
\hline $\mathrm{Ca}$ & - & - & - & - & - & - & 0,24 & 0,14 \\
\hline $\mathrm{Mg}$ & - & - & - & - & - & - & 0,25 & 0,15 \\
\hline $\mathrm{Mn}$ & 0 & 0 & 0,03 & 0,03 & 0,02 & 0,03 & 0,04 & - \\
\hline $\mathrm{Zn}$ & 0,04 & - & 0 & - & - & - & - & - \\
\hline $\mathrm{Fe}$ & 0,8 & 0,01 & 0,01 & - & - & - & 0,59 & 0,43 \\
\hline Co & - & - & 0 & 0 & - & - & - & - \\
\hline $\mathrm{Cu}$ & 0,09 & 0,07 & 0,09 & 0,1 & 0,01 & 0,01 & - & - \\
\hline $\mathrm{Na}$ & 3,8 & 10,2 & 15,6 & 15,2 & 12,3 & 8,5 & 9,1 & 9,06 \\
\hline $\mathrm{Ni}$ & 0,29 & 0,016 & 0,024 & 0,036 & 0,024 & 0,076 & 0,032 & 0,021 \\
\hline
\end{tabular}

Fonte: COMAR, 2009 (27). 
O intervalo de valores de DQO variou de 4297 a $589 \mathrm{mg} \mathrm{L}^{-1}$, com valor médio de redução de $86 \%$ ao fim do tratamento. Caixeta, Cammarota e Xavier (7) obtiveram reduções de até 90,6\% para efluente de abatedouro de bovinos e suínos com biodigestor UASB em pleno funcionamento.

Apesar de os valores de DBO e DQO terem apresentado redução no efluente, essas reduções poderiam ter ocorrido mais intensamente. Esse fato ocorreu em virtude dos biodigestores estarem em fase de partida, não tendo alcançado seu melhor desempenho. Os ajustes na biodigestão anaeróbia, como tempo de retenção hidráulica (TRH), vazão, inóculo, retenção de sólidos antes do ponto P4 (afluente dos biodigestores), bom funcionamento da caixa de gordura, dos tanques de equalização, da peneira, entre outros, estão sendo testados.

Para os valores de ST e SV não houve redução significativa, o que não causa limitação para a reciclagem dos resíduos, uma vez que se encontram em níveis relativamente baixos. Os valores de $\mathrm{pH}$ estiveram na faixa de 6,92 e 7,47, dentro do padrão de lançamento que, de acordo com NT-202 R10, é de 5,0 a 9,0 (8).

Os nutrientes N, P, Mn e o elemento Na tiveram seus valores médios de concentração reduzidos ao longo do tratamento; já o K, Ca, Mg, Zn tiveram aumento em sua concentração nos ponto P7 e P8.

Com base nos valores de metais pesados avaliados no resíduo $\mathrm{Cu}, \mathrm{Fe}, \mathrm{Zn}$ e Mn, não há limitação para seu uso na fertirrigação. Já o Ni no ponto P1 apresentou valor superior ao recomendado, porém a partir do segundo ponto o valor alcançou o limite para disposição (9).

Não houve ocorrências de ovos viáveis de helmintos e Salmonella sp. na saída dos biodigestores e saída das lagoas de polimento, o número mais provável de coliformes fecais na saída dos biodigestores foi de $114,5 \mathrm{ml} \mathrm{L}^{-1}$ e coliformes fecais de $86,0 \mathrm{ml} \mathrm{L}^{-1}$, o que, de acordo com a resolução Conama n. 375/2005, pode ser utilizado para fertirrigação de hortaliça. Nas lagoas de polimento, o número mais provável de coliformes totais e fecais esteve abaixo do nível de detecção, o que demonstra a eficiência do sistema de tratamento.
2. Ueno H, Gonçalves PC. Manual para diagnóstico das helmintoses de ruminantes. Porto Alegre: Universidade Federal do Rio Grande do Sul; 1994.

3. Schoebitz R, Montes L. Indicadores de contaminacion bacteriológica y presencia de Salmonella em água del Rio Valdivia (Chile). Archives Medicine Veterinary. 1978;81(3):353-60.

4. HoltJG. Bergeys manual of determinative bacteriology. 9th ed. Philadelphia: Williams e Wilkins; 1994.

5. AWWA/APHA/WEF Standard Methods. Standard methods for the examination of water and wastewater. 17th ed. Washington; 1995.

6. Braile PM. Manual de tratamento deáguas residuárias industriais. São Paulo: CETESB; 1993.

7. Caixeta CET, Cammarota MC, Xavier AMF. Avaliação de nova proposta de separador trifásico em reatores UASB no tratamento de efluentes de frigoríficos. In: Anais do $19^{\circ}$ Interamerican Congress of Chemical Engineering, 2000, Águas de São Pedro: Interamerican Congress of Chemical Engineering; 2000 .

8. Giordano G. Tratamento e controle de efluentes industriais. 2004 [acesso em 7 nov. 2005]. Disponível em: http:/ /www.ufmt.br/esa/Modulo_ II_Efluentes_Industriais/Apost_EI_2004_1ABES_ Mato_Grosso_UFMT2.pdf.

9. Leons G, Moscosso CJ. Tratamento e uso de águas residuárias. Campina Grande: UFPB; 1999.

Recebido: 02/06/2009 Received: 06/02/2009

Aprovado: 03/09/2009 Approved: 09/03/2009

\section{Referências}

1. Unesco. OurDiversity. Report of the world commission on culture and development. France: Egoprim; 1996. 